\title{
Modelling the Determinants of ICTs Policy Formulation in Technical and Vocational Education in Nigerian Institution of Higher learning
}

\author{
Babawuro Shu'aibu' ${ }^{1 *}$, Muhammad Sukri bin Saud', Hassan Bello², \\ Yusri Kamin ${ }^{1}$ and Yahaya Buntat ${ }^{1}$ \\ 'Faculty of Education, Universiti Teknologi Malaysia, 81310, Skudai, Johor Bahru, \\ Darul Ta'azim, Malaysia; bbwuro@yahoo.com \\ ${ }^{2}$ Vocational and Technology Education, Abubakar Tafawa Balewa University, P. M. B. 0248, \\ Bauchi, Bauchi State, Nigeria; hassanbello2005@yahoo.com
}

\begin{abstract}
Developing sound and relevant Information and Communication Technologies (ICTs) policies in education and higher learning institutions in particular is still not exhausted in some developing countries around the world. Despite ICTs adoption in education, mostly higher institutions of learning deploy the use of such facilities without relevant policies guide showing how, what, where and when these facilities are going to be utilised. In order to develop ICTs policy in those institutions, specific areas for consideration need to be developed. Therefore, this study aimed at developing a model based on linear regression and Structural Equation Modelling (SEM) of significant determinants that need to be given priority during ICTs policy formulation in Technical and Vocational Education (TVE) in Nigerian higher institutions of learning. One hundred and forty (140) respondents comprised of policy makers, administrators and lecturers responded to a structured questionnaire addressing research question and its corresponding hypothesis. A conceptual model developed consisted of 7 observed variables that will serve as areas that should be considered in ICTs policy for TVE programmes in Nigeria. A model was recommended for adoption and implementation in higher institutions offering TVE in Nigeria
\end{abstract}

Keyword: ICT policy, Technical and Vocational Education.

\section{Introduction}

ICTs is becoming a live wire driving the educational development of every nation [11], its use in modernization of teaching methods in developing countries is well documented [12]. ICT policy in education therefore, becomes a switch regulating the operation of ICT facilities. It was found to be a significant instruments that affect the classroom application of ICTs [14] educational ICT policy comprised of objectives and vision on the way educational system operates; how students, parents, teachers and the entire school community tend to utilized the ICT facilities [8]. ICT policy in education is becoming significant area that is continued to be acknowledged by educational stakeholders. Though, not much research has been done in the area of ICT policy formulation in TVE; studies carried out in general education revealed ICT policy should be considered as a universal phenomena that found root in school culture and should cover vision, finance, infrastructure, professional development, and curriculum [16].

* Corresponding author:

Babawuro Shu'aibu (bbwuro@yahoo.com) 
It is no longer a news that some developing countries around the world are having ICT in education policy in place; South Africa and Chile for example [4]. It is also evident that ICTs in education policies in these countries made provision on staff professional development and provisions of ICT facilities. Some studies have proposed ICT policy for non users describing them as those lacking ICT skills and inability to have access [19]. The first step toward integrating ICTs in education or schools is developing an ICT policy; a document containing detail description of what the school intends to achieve as a result of ICTs deployment. To provide guide on the way and manner ICT policy is to be developed, an online tool has been developed to that effect [18].

It is acknowledged that an appreciable number of public institutions of higher learning in Nigeria integrated ICTs in aspect of teaching, learning and administration; but institutions are doing so without appropriate guiding document (ICT policy); in that Nigerian National ICT policy is inadequate to make provision on the educational application of ICTs [20] and institutions may not have developed any. In view of that, this research aimed at identifying important areas for consideration in the development of ICTs policy for Technical and Vocational Education (TVE) programmes in higher institutions in Nigeria. Specifically, the research developed conceptual model based on the outcome of the result.

\section{Objective of the Research}

The research aimed at developing a conceptual model on the important areas considered to be significant determinants for incorporation in ICTs policy for higher institutions of learning offering TVE in Nigeria. Specifically, Regression analysis and Structural Equation Modelling (SEM) were used to analyse the quantitative data collected from the respondents that participated in the research. The important areas in which a conceptual model was based on are: Provision on Confidentiality, Provision on Information Security, Provision on Intellectual Property, Provisions on Safety Requirement, Provisions on handling of equipments, Provisions on students' general conduct, Provisions on access to ICT facilities/tools, Provisions on Hardware and software requirements, Provisions on maintenance, Provisions on management information System (MIS).

\section{Materials and Methods}

\subsection{Research Design}

A survey research design was employed for data collection at five higher institutions comprised of Universities, Polytechnics and Colleges of Education (Technical) offering Technical and Vocational Education located in north-eastern Nigeria. Analysis involving correlations was done on the initial model to verify significant influence of observed variables on the unobserved variable. A hypothesized initial measurement model was tested for fit indices and compared against the default model.

\subsection{Research Sample and Sampling Procedure}

A sample of 140 participants were selected using a purposive sampling technique from a sample of five higher institutions of learning in north-eastern Nigeria. Only institutions owned and controlled by the Federal Government of Nigeria based on their similar and harmonised characteristics in admission, curriculum and graduation requirements were involved in the selection of respondents for this research. Purposive sampling technique was employed in that, only staffs from TVE programmes/departments have participated in the research.

\subsection{Instrument and Instrumentation}

A 40 items questionnaire initially developed was modified to 24-items, 4-point scale after validation and pilot study. The questionnaire developed comprised of significant areas considered determinants for consideration in developing ICTs policy for TVE programmes. A questionnaire was used in the collection of data on the opinions of policy makers, administrators and lecturers on areas considered important to be included in ICTs policy formulation for TVE programme in Nigerian higher institutions of learning.

\section{Result}

The research question with its corresponding hypothesis that guided the conduct of the research was answered and tested respectively. The research question reads; what significant areas are considered determinants for incorporation in ICTs policy for TVE programmes in Nigeria? And corresponding null hypothesis (Ho) states that areas for 
incorporation in ICTs policy formulation for TVE do not differ significantly.

\subsection{Regression Analysis}

Step-wise criteria was selected in SPSS software for regression analysis. The analysis was computed and the result in Table 1 was obtained.

Table 1. presents the result of Linear Regression Analysis sing the 'Stepwise Criteria', although a significant regression model has emerged with $\mathrm{F}_{7,140}=1045.929, \mathrm{p}<0.05$, $\mathrm{R}^{2}=.989,7$ Predictor Variables: Provisions on access to ICT Facilities, Provisions on Safety Requirement and Provisions on Hardware and software requirements, Provision on students general conduct, Provision on MIS, Provision on Maintenance and Provision on Confidentiality having $\mathrm{B}=.172, .177, .164, .157, .133, .111$ and .102 respectively setting $\mathrm{p}<0.05$ are significant determinants for incorporation in developing ICTs policy in TVE. Other determinants such as provisions on information security, provisions on intellectual property and provisions on handling of equipment have less significant contribution toward an effective ICTs policy in TVE, i.e. to say, they are not considered as important areas for consideration in formulating ICT policy in TVE in Nigeria's Higher Institutions of Learning. Table 2, shows a summary of the seven most significant determinants toward effective ICTs policy in TVE.

Table 1. Regression analysis result on the significant determinants for effective policy on ICTs in TVE

\begin{tabular}{|c|c|c|c|c|c|c|c|c|}
\hline \multicolumn{2}{|r|}{ Significant Determinants for ICTs Policy in TVE } & \multirow{2}{*}{$\begin{array}{c}\text { U C } \\
\text { B }\end{array}$} & \multicolumn{3}{|c|}{ S C } & & \multicolumn{2}{|c|}{$95 \% \mathrm{~B}$} \\
\hline & & & S. E. & Beta & $\mathrm{t}$ & Sig. & & B \\
\hline 1 & a) Prov. on access to ICT facilities./tools & .704 & .016 & .980 & 45.251 & .000 & .673 & .735 \\
\hline \multirow{2}{*}{2} & a) Prov. on access to ICT facilities./tools & .382 & .041 & .532 & 9.209 & .000 & .300 & .465 \\
\hline & b) Prov. on Safety Requirement & .351 & .043 & .467 & 8.084 & .000 & .265 & .438 \\
\hline \multirow{3}{*}{3} & a) Prov. on access to ICT facilities./tools & .258 & .040 & .359 & 6.395 & .000 & .178 & .338 \\
\hline & b) Prov. on Safety Requirement & .261 & .039 & .346 & 6.629 & .000 & .182 & .339 \\
\hline & c) Prov. on Hard/software requirements & .230 & .038 & .302 & 6.052 & .000 & .154 & .305 \\
\hline \multirow{4}{*}{4} & a) Prov. on access to ICT fac./tools & .180 & .042 & .251 & 4.267 & .000 & .096 & .264 \\
\hline & b) Prov. on Safety Requirement & .209 & .039 & .278 & 5.423 & .000 & .132 & .286 \\
\hline & c) Prov. on Hard/software requirements & .205 & .036 & .270 & 5.761 & .000 & .134 & .276 \\
\hline & d) Prov. on students general cond. & .165 & .042 & .213 & 3.921 & .000 & .081 & .249 \\
\hline \multirow[t]{5}{*}{5} & a) Prov. on access to ICT fac./tools & .136 & .043 & .189 & 3.117 & .003 & .049 & .222 \\
\hline & b) Prov. on Safety Requirement & .168 & .040 & .223 & 4.195 & .000 & .088 & .247 \\
\hline & c) Prov. on Hard/software requirements & .175 & .036 & .230 & 4.867 & .000 & .103 & .246 \\
\hline & d) Prov. on students general cond. & .160 & .040 & .206 & 3.962 & .000 & .080 & .241 \\
\hline & e) Prov. on mgt. inf. System (MIS) & .123 & .044 & .164 & 2.799 & .006 & .036 & .211 \\
\hline \multirow[t]{6}{*}{6} & a) Prov. on access to ICT fac./tools & .137 & .043 & .190 & 3.200 & .002 & .052 & .222 \\
\hline & b) Prov. on Safety Requirement & .130 & .043 & .173 & 2.999 & .004 & .044 & .217 \\
\hline & c) Prov. on Hard/software requirements & .149 & .037 & .196 & 3.985 & .000 & .075 & .224 \\
\hline & d) Prov. on students general cond. & .150 & .040 & .193 & 3.732 & .000 & .070 & .229 \\
\hline & e) Prov. on mgt inf. System (MIS) & .120 & .043 & .159 & 2.761 & .007 & .033 & .206 \\
\hline & f) Provisions on maintenance & .076 & .038 & .102 & 2.011 & .048 & .001 & .152 \\
\hline \multirow[t]{7}{*}{7} & a) Prov. on access to ICT fac./tools & .123 & .042 & .172 & 2.912 & .005 & .039 & .208 \\
\hline & b) Prov. on Safety Requirement & .111 & .044 & .167 & 2.535 & .013 & .024 & .197 \\
\hline & c) Prov. on Hard/software requirements & .125 & .039 & .164 & 3.225 & .002 & .048 & .202 \\
\hline & d) Prov. on students general cond. & .145 & .039 & .157 & 3.680 & .000 & .066 & .223 \\
\hline & e) Prov. on mgt inf. System (MIS) & .100 & .044 & .133 & 2.284 & .025 & .013 & .186 \\
\hline & f) Provisions on maintenance & .083 & .037 & .111 & 2.215 & .030 & .008 & .157 \\
\hline & g) Provision on Confidentiality & .084 & .041 & .102 & 2.030 & .046 & .002 & .167 \\
\hline
\end{tabular}


Table 2. Summary on the most significant determinants for effective policy on ICTs in TVE

\begin{tabular}{|c|c|c|c|c|}
\hline Most Significant Determinants & $\mathbf{R}$ & $\mathbf{R}^{2}$ & Adjusted $\mathrm{R}^{2}$ & S. E. \\
\hline 1 Provisions on access to ICT facilities/tools & $.980^{\mathrm{a}}$ & .961 & .960 & .49922 \\
\hline 2 Provisions on Safety Requirement & $.989^{c}$ & .978 & .977 & .37565 \\
\hline 3 Provisions on Hardware and software requirements & $.992^{\mathrm{d}}$ & .985 & .984 & .31422 \\
\hline 4 Provisions on students general conduct & $.994^{\mathrm{e}}$ & .987 & .987 & .28984 \\
\hline 5 Provisions on mgt. information System (MIS) & $.994^{\mathrm{f}}$ & .988 & .988 & .27834 \\
\hline 6 Provisions on maintenance & $.994^{\mathrm{g}}$ & .989 & .988 & .27319 \\
\hline 7 Provision on Confidentiality & $.995^{\mathrm{h}}$ & .989 & .989 & .26795 \\
\hline
\end{tabular}

The highest value of Adjusted $\mathrm{R}^{2}$ of .989 in Table 2 indicates that the model account for $98.9 \%$ variance in the areas considered being important in ICT integration in TVE Policy Formulation. This further reveals that these seven items are most significant determinants toward formulating effective ICTs policy in Technical and Vocational Education in higher institutions in Nigeria.

\subsection{Structural Equation Modelling Using AMOS}

Regression Analysis computed earlier revealed the contribution of each of the significant determinant to the model; it has not indicated the influence and relationship that exist between the determinants, variables and the latent variable. This necessitated the use of AMOS to enable us come up with the structure of the model and how observed variables relates within and between them and major variable (latent variable). The distinct feature between Regression Analysis and Structural Equation Modelling (SEM) with latent variables is that, the observed variables in later give room for measurement error to be estimated randomly. Thus factor loadings between observed variables and latent variables are presented. Several indicators, (observed variables) measures one latent variable in Structural Equation Modelling (SEM).

\subsection{Model Evaluation}

The model was evaluated using chi-square $\left(\mathrm{x}^{2}\right)$, degree of freedom (df), significance level ( $\mathrm{p}<0.05)$, and covariance statistics. Other parameters such as Goodness of Fit Index (GFI), Tuker Lewis Index (TLI), and Comparative Fit Index (CFI) are shown to explain the variance. Root Mean Square Residual (RMR) and Root Mean Square Error of Approximation (RMSEA) were provided to describe mean covariance residual and fit index precision respectively.
Internal consistency of the areas considered important for ICT integration in TVE were determined using cronbach's alpha statistics. The areas are: Provision on Confidentiality (0.78), Provision on Information Security (.079), Provision on Intellectual Property (0.82), Provisions on Safety Requirement (0.85), Provisions on handling of equipments (0.76), Provisions on students' general conduct (0.84), Provisions on access to ICT facilities/tools (0.87), Provisions on Hardware and software requirements (0.75), Provisions on maintenance (0.86), Provisions on management information System (MIS) (0.84). From the results, all items under major areas for consideration were found to be reliable. In that no values below 0.50 (unreliable) and also all the variables are above adequate of 0.70 which is classified as conventional. Table 3 shows the cronbach's alpha reliability results.

After the reliability coefficients of the major variables were obtained, measurement model was then tested using SPSS-AMOS version 18. Chi-square $\left(\grave{W}^{2}\right)$, df, GFI, CFI, RMSEA, TLI and P standard values (Table 4) were used for comparison to determine the fitness or other wise of both the measurement model and a modified model.

Table 5 shows the computed values for model fit indices on measurement model (initial model) for ICTs in TVE policy formulation. Based on the result above, the measurement model does not fit well; a value of 4.23 was obtained for $\left(\grave{\mathrm{W}}^{2}\right) / \mathrm{df}$ compared to the standard value (<3.00), also GFI (0.67), TFI (0.54), CFI (0.46), IFI (0.78), RMR (0.13) and RMSEA (0.21) were all below the normal range of values for a model fit. This has resulted to the modification of the initial model by removing observed variables that possibly contributes less to the model goodness of fit. Figure 1 present the structure of the measurement model.

Figure 1 shows a total of 10 observed variables (PF1 PF10) that were expected to predict unobserved variable (Policy Formulation). The variables were presented as items 
Table 3. Cronbach's a Reliability Results on Major Areas for ICT integration in TVE

\begin{tabular}{lcc}
\hline Major Areas (Latent Variables) in the Model & Cronbach's $\boldsymbol{~}$ & No. of Items \\
\hline Provision on Confidentiality & 0.78 & 3 \\
Provision on Information Security & 0.79 & 3 \\
Provision on Intellectual Property & 0.82 & 3 \\
Provisions on Safety Requirement & 0.85 & 3 \\
Provisions on handling of equipments & 0.76 & 3 \\
Provisions on students general conduct & 0.84 & 3 \\
Provisions on access to ICT facilities/tools & 0.87 & 3 \\
Provisions on Hardware and software requirements & 0.75 & 3 \\
Provisions on maintenance & 0.86 & 3 \\
Provisions on management information System (MIS) & 0.84 & 3 \\
\hline
\end{tabular}

Table 4. Default model fit indices

\begin{tabular}{lc}
\hline Model Fit Indices & Range Values \\
\hline 1. Chi-square $\left(\grave{W}^{2}\right) / d f$ & $<3.00$ \\
2. Goodness of Fit (GFI) & $\geq 0.9$ \\
3. Tukers-Lewis Index (TFI) & $\geq 0.9$ \\
4. Comparative Fix Index (CFI) & $\geq 0.9$ \\
5. Incremental Fit Index (IFI) & $\geq 0.9$ \\
6. Root Mean Square Residual (RMR) & $\leq 0.05$ \\
7. Root Mean Square Error of Approximation & $\geq 0.9$ \\
(RMSEA) & \\
\hline
\end{tabular}

Table 5. Measurement model for ICTs in TVE policy formulation

\begin{tabular}{|c|c|c|c|}
\hline Model Fit Indices & Comp values & Range Values & $\mathrm{P}$ \\
\hline 1. Chi-square $\left(\grave{\mathrm{W}}^{2}\right) / \mathrm{df}$ & 4.23 & $<3.00$ & \\
\hline 2. Goodness of Fit (GFI) & 0.67 & $\geq 0.9$ & \\
\hline 3. Tukers-Lewis Index (TFI) & 0.54 & $\geq 0.9$ & \\
\hline $\begin{array}{l}\text { 4. Comparative Fix Index } \\
\text { (CFI) }\end{array}$ & 0.46 & $\geq 0.9$ & .000 \\
\hline 5. Incremental Fit Index (IFI) & 0.78 & $\geq 0.9$ & \\
\hline $\begin{array}{l}\text { 6. Root Mean Square Residual } \\
\text { (RMR) }\end{array}$ & 0.13 & $\leq 0.05$ & \\
\hline $\begin{array}{l}\text { 7. Root Mean Square Error of } \\
\text { Approximation (RMSEA) }\end{array}$ & 0.21 & $\leq 0.05$ & \\
\hline
\end{tabular}

in a questionnaire, and were refers to PF1- (provisions on confidentiality), PF2 - (provisions on information security), PF3 - (provisions on intellectual property/copy right), PF4 (provisions on safety requirements), PF5 - (provisions on handling of equipment), PF6 - (provisions on students general conduct), PF7 - (provisions on access to ICT facilities), PF8 - (provisions on hardware and software requirement),

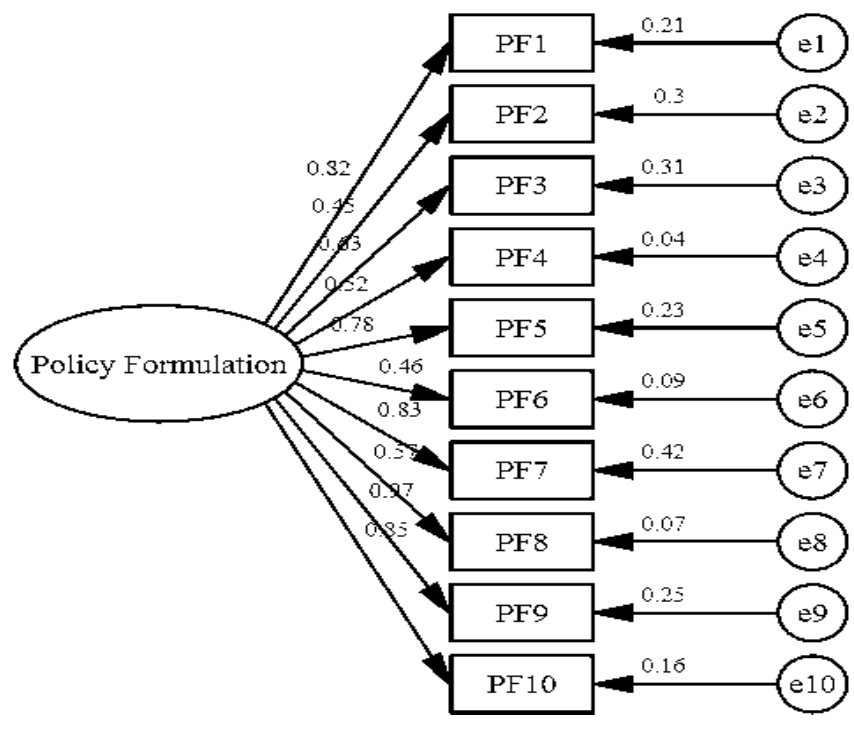

Figure 1. Measurement Model on Policy Formulation.

PF9 - (provisions on maintenance) and PF10 - (provisions on management information system (MIS).

Inspection of the model reveals that the main source that makes it unfit lies on the 3 items that are found to be not siginifcant in the model, these items are: provisions on information security, provisions on intellectual property/ copy right and provisions on handling of equipment. Therefore, those items were removed and model was re-tested to yield the modified model with good fit obtained in figure 2.

Table 6 shows the computed values for model fit indices on modified model for ICTs in TVE policy formulation. Based on the result above, the modified model fit well; a value of 4.23 was obtained for $\left(\mathrm{W}^{2}\right) / \mathrm{df}$ compared to the standard value $(<3.00)$, also GFI (0.98), TFI (0.96), CFI 


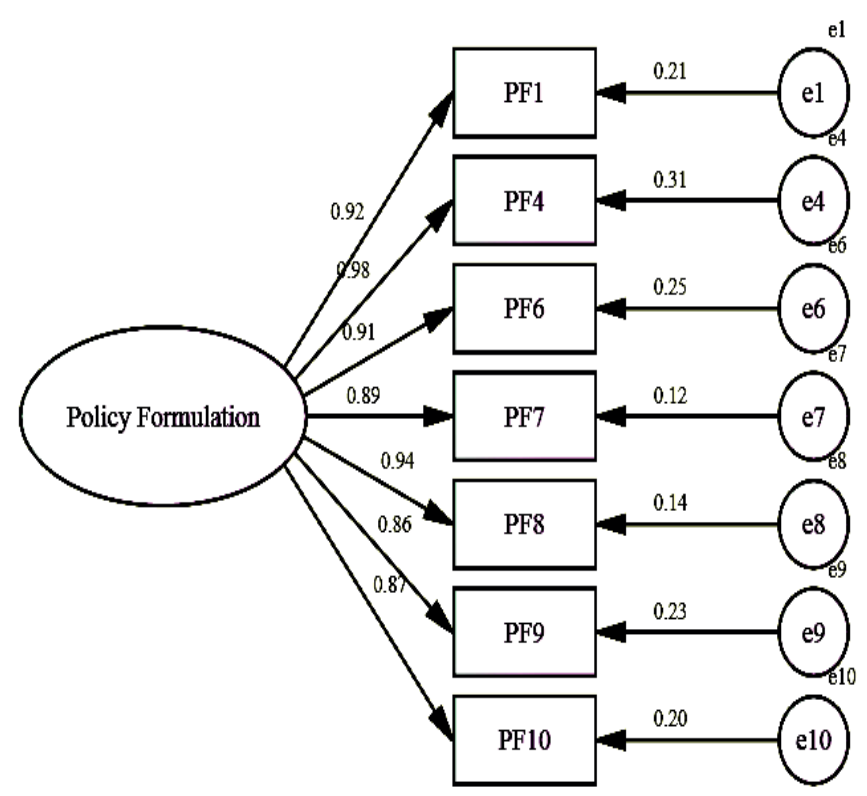

Figure 2. Modified model for Policy formulation.

Table 6. Modified model for ICTs in TVE policy formulation

\begin{tabular}{|c|c|c|c|}
\hline Model Fit Indices & Comp values & Range Values & $\mathrm{p}$ \\
\hline 1. Chi-square $\left(\grave{\mathrm{W}}^{2}\right) / \mathrm{df}$ & 2.10 & $<3.00$ & \\
\hline 2. Goodness of Fit (GFI) & 0.98 & $\geq 0.9$ & \\
\hline $\begin{array}{l}\text { 3. Tukers-Lewis Index } \\
\text { (TFI) }\end{array}$ & 0.96 & $\geq 0.9$ & \\
\hline $\begin{array}{l}\text { 4. Comparative Fix Index } \\
\text { (CFI) }\end{array}$ & 0.91 & $\geq 0.9$ & .000 \\
\hline $\begin{array}{l}\text { 5. Incremental Fit Index } \\
\text { (IFI) }\end{array}$ & 0.94 & $\geq 0.9$ & \\
\hline $\begin{array}{l}\text { 6. Root Mean Square } \\
\text { Residual (RMR) }\end{array}$ & 0.023 & $\leq 0.05$ & \\
\hline $\begin{array}{l}\text { 7. Root Mean Square } \\
\text { Error of Approximation } \\
\text { (RMSEA) }\end{array}$ & 0.031 & $\leq 0.05$ & \\
\hline
\end{tabular}

(0.91), IFI (0.94), RMR (0.023) and RMSEA (0.031) at $\mathrm{P}<.05$, were within the accepted region of values for a model fit. Therefore, the modified model yielded good fit indices and is therefore accepted.

Figure 2, shows structural link between seven variables (PF1, PF4, PF6, PF7, PF8, PF9 and PF10) and Policy Formulation in the modified model. This further reveals that 3 variables (PF2, PF3 and PF5) were removed from the initial model due to their insignificant correlation with policy formulation. Therefore, from the modified model (Figure 2) it can be deduced that to formulate an effective
ICTs policy in TVE, the aspect of confidentiality, safety, students conduct, access to facilities, hardware and software requirements, maintenance and management information system should be highly considered. The presentation of conceptual model for ICTs in TVE policy formulation is shown in Figure 3.

Conceptual model presented in Figure 3, presented areas identified after SEM analysis to be significant variables in consideration for incorporation in ICTs policy document in TVE in higher institutions in Nigeria. In the conceptual model, it can be observed that provision on safety requirements is one of the areas found to be reflected first in the policy according to the respondents. Provision on hardware and software requirement is second in the hierarchy followed by provision on confidentiality of information which is the third as reflected in the model. Provision on student's general conduct is also found to be very important for consideration when ICT policy is to be developed in TVE programmes in Nigeria.

The conceptual model further indicates the provision on access to ICT facilities, provision on management information system and provision on maintenance are also significant areas for consideration when sound ICT policy is to be developed in TVE in Nigeria.

\section{Discussion}

Seven important areas found as worthy for consideration and incorporation in the policy on ICTs for TVE; the pol-

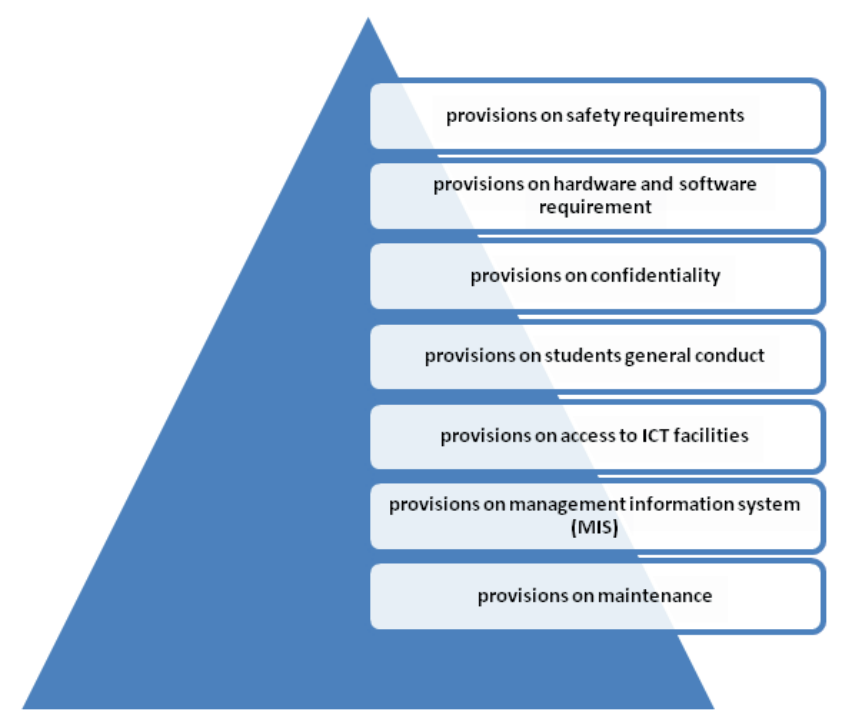

Figure 3. Conceptual model of ICTs in TVE policy formulation. 
icy according to the findings of this research should make necessary provisions on accessibility to ICTs facilities by users in the TVE programme (staff, students, non student, entire institution community). Success in ICTs integration in general education not TVE in particular, receives concerned by scholars/researchers due to is numerous links to sound policies [17]. Moreover, policy on ICTs is one of the first thing to be put in place for successful integration of ICTs [5], hence, ICT policy paves way for solution that normally arises in the process of integration of ICTs in education [7]. On the same vein, ICT policy is document that leads to the successful integration of ICTs[3].

Policy documents on ICTs in higher institutions of different countries of the world were developed and made provisions on access to ICTs facilities. For example, University of Tasmania's Policy on ICTs referred to as 'ICT services and facilities use policy' in 2010 and reviewed on $1^{\text {st }}$ June, 2011 had reflected sub section on 'access to facilities', and on 'accessing the internet and online services', (University of Tasmania, 2010). This type of policy document and provisions there in, agrees to the findings of this research that 'provisions on access to ICTs facilities to all users in the higher institutions offering TVE in Nigeria should be reflected in policy on ICTs in TVE. While some institutions outside Nigeria have ICT policy document, Nigerian higher institutions academicians such as [1] recommended sound ICT policy in education.

Some higher institutions that are having ICTs policy use it in defining the eligibility of whoever shall be the users of ICT facilities and the nature of facilities accessible to different users at a time. Thus, the conditions for the access sometimes are equally indicated to serve as guide on what users can view and down load interns of information. To some extent, ICTs policy makes provision on the jurisdiction of IT administrators to either allocate or withdraw accessibility to whomever dissatisfied or violate the laid down rules and regulations governing ICTs use. In some cases, the policy on ICTs recognises other users who need to access ICTs facilities outside the institutions. Access to ICTs facilities also referred to the availability of the facilities for teaching and learning and other administrative activities [4] not only its usability, in which finding of this research also focuses on how ICTs can be available for TVE activities. In some cases, policy makers regard ICTs accessibility as an issue that need political interpretation especially at the end of twenty first century [2].

The second finding with regards to ICTs policy formulation has to do with the policy making provisions on software and hardware requirements. This finding explained the position of administrators, policy makers and lecturers on the specific software and hardware that should be required for use in TVE. On the hand, it was observed by the respondents that not all software and hardware ICTs are suitable for TVE, specific ones need to be use and for that, a specific clause is equally reflected in the policy to guide ICTs users or IT managers on the specific software or hardware to be used in TVE, especially nowadays that hardware and software are rapidly changing which require schools to have changes also in a rapid manner [15]. Consequently, the finding of this research is in agreement with the findings that successfully ICTs integrated institutions were achieved it using a well guided ICTs policy document [3].

It was also observed by several researchers that apart from ICTs policy 's relevancy to software and hardware requirements, it should have incorporated the way instructional activities is being affected with ICTs [7]. This has serious implication on the need for ICTs policy to make specific provisions on the specification for the software and hardware to be adopted for teaching learning and other day to day activities in TVE; this equally supported the finding of this research. Consequently, Policy on ICT in education reflects the type of software that should be put in place for teachers and the school. This is because, computer itself is dependent on the nature of software it can run [10].

Finding of this research that is related to provisions on students general conduct in ICTs policy formulation in TVE aspire by policy makers, administrators and lecturers that provision be made to include students general conduct when developing a policy on ICTs in TVE in Nigeria. Students' general conduct can be interpreted in such a manner in which they conduct themselves in the use of ICT facilities, especially when they are associating with friends through accessing and interacting on social networks like face book, twitter, twoo, e-mail etc. The finding also suggest that an ICTs policy, helps articulate and motivate users; which are by and large provides a broader circumstance for transformation and helps people to change [9]. However, the need for ICT policy statement on general conduct of students as found out in this research was noted by scholars like Kozma who states that "Within education, socially oriented ICT policies can offer to connect classrooms across cultures, increase parental participation, provide student access to specialized educational services, and extend the delivery of education to remote populations" [9]. 
This research shows the importance for the policy on ICTs to make provisions on maintenance of ICT facilities; network and network accessories, computers, electricity supply equipments, telephones, video players/recorders, etc, needs to be regularly maintained for effective operation. The issue of maintenance is reflected by the outcome of the study in South Africa and Chile, that ICT infrastructure was not receiving technical support due to lack of support by the ministry in charge of that aspect [4]. This could be attributed to the fact that there may be no specific clause in their ICT policy on the maintenance of ICTs infrastructure, which may possibly affect the nature of commitment by ICT coordination bodies. Therefore, based on the findings of this research, specific provisions should be made in the ICTs policy for TVE to cater for the maintenance of ICTs infrastructure. In addition, a university based ICT policy documents supports the finding of this research in which a clear statement reads; 'University's ICT directorate and that procurement and maintenance of internet connectivity is to be provided to the University community through the ICT directorate' [13].

Confidentiality of information is one of the important components found to be included in ICTs policy in TVE in Nigeria according to the results of this research. It can be noted that information confidentiality is sometimes a neglected area [6] in some of the ICT policy documents. However, due to the importance, of provisions on confidentiality in ICT policy, institutions of higher learning in Africa such Addis Ababa University ICT policy reflected an aspect of confidentiality of information.

\section{Conclusion}

ICT policy for TVE higher institutions in Nigeria is a switch regulating and controlling the application and activities on the use of ICT. The important of sound policy provisions is clearly shown in this research based on the position of policy makers, administrators and lecturers of such institutions. Provisions on confidentiality of information, on access to ICT facilities, management information system etc, were outlined to be very prominent for incorporation of policy statements for guidance on the way application of ICT are done to provide services. Conceptual model developed indicates the level of importance of the areas in order of priority for implementation depending on which among the areas institutions feels it should begin with. In conclusion, the model is recommended for proper adoption to various institutions that offer TVE at Diploma,
Higher Diploma, Degree and Postgraduate levels of education in Nigeria.

\section{References}

1. Aduke A F (2008). Usage and Challenges of Information Communication Technology (ICT) in teaching and learning in Nigerian Universities, Asian Journal of Information Technology, vol 7(7), 290-295.

2. Anderson R, and Ainley J (2010). Technology and learning: access in schools around the world. In P. Editors-in-Chief: Penelope, B. Eva, E. B. Barry McGawA2 - Editors-in-Chief: Penelope Peterson \& M. Barry (Eds.), International Encyclopedia of Education, 3rd Edn. , 21-33, Oxford: Elsevier.

3. Baylor A L, and Ritchie D (2002). What factors facilitate teacher skill, teacher morale, and perceived student learning in technology-using classrooms? Computers \& Education, vol 39(4), 395-414.

4. Blignaut A S, Hinostroza J E et al. (2010). ICT in education policy and practice in developing countries: South Africa and Chile compared through SITES 2006, Computers \& Education, vol 55(4), 1552-1563.

5. Bryderup I, and Kowalski K (2002). The role of local authorities in the integration of ICT in learning, Journal of Computer Assisted Learning, vol 18(4), 469-479.

6. Cziraky D (2000). Information and Communication Technology (ICT) Policy in the Central and South Eastern Europe, Croatian International Relations Review, vol 6(20/21).

7. Gülbahar Y (2007). Technology planning: A roadmap to successful technology integration in schools, Computers \& Education, vol 49(4), 943-956.

8. Kozma R B (2008). Comparative analysis of policies for ICT in education, International Handbook of Information Technology in Primary and Secondary Education, vol 20, 1083-1096.

9. Kozma R B (2010). Relating Technology, Education Reform and Economic Development. In P. Penelope, B. Eva \& M. Barry (Eds.), International Encyclopedia of Education, 81-87, Oxford: Elsevier.

10. Kozma R B, and Isaacs S (2011). Transforming Education: The Power of ICT Policies: UNESCO.

11. Mujumdar D (2009). ICT in Education. Available from http://ssrn.com/abstract $=2179744$

12. Nkenlifack M, Nangue R, et al. (2011). ICT for Education, (IJACSA) International Journal of Advanced Computer Science and Applications, vol 2(4), 124-133.

13. Open E. Resources (2010). Information and Communication Technology (ICT) Policy; University of Jos Nigeria, Building African Education Capacity through Openness. Retrieved from Building African Education Capacity though Openness website: www.oerafroca.org 
14. Tondeur J, Van Keer H, et al. (2008). ICT integration in the classroom: Challenging the potential of a school policy, Computers \& Education, vol 51(1), 212-223.

15. Vanderlinde R, and van Braak J (2010). The e-capacity of primary schools: Development of a conceptual model and scale construction from a school improvement perspective, Computers \& Education, vol 55(2), 541-553.

16. Vanderlinde R, van Braak J, et al. (2011). ICT policy planning in a context of curriculum reform: Disentanglement of ICT policy domains and artifacts, Computers \& Education, vol 58(4), 1339-1350.

17. Vanderlinde R, van Braak J, et al. (2009). Educational technology on a turning point: curriculum implementation in
Flanders and challenges for schools. Educational Technology Research and Development, vol 57(4), 573-584.

18. Vanderlinde R, van Braak J, et al. (2010). Using an online tool to support school-based ICT policy planning in primary education. Journal of Computer Assisted Learning, 26(5), 434-447.

19. Verdegem P, and Verhoest P (2009). Profiling the non-user: Rethinking policy initiatives stimulating ICT acceptance. Telecommunications Policy, vol 33(10-11), 642-652.

20. Yusuf M O (2005). Information and communication technology and education: Analysing the Nigerian national policy for information technology. International Education Journal, vol 6(3), 316-321. 